\title{
Metode latihan dan koordinasi mata tangan meningkatkan akurasi forehand sidespin service tenis meja
}

\author{
Indra Safari *, Entan Saptani \\ Universitas Pendidikan Indonesia. Jl. Dr. Setiabudhi No. 229 Bandung 40154 Jawa Barat - Indonesia \\ * Corresponding Author. Email: indrasafari77@upi.edu
}

Received: 22 August 2019; Revised: 26 December 2019; Accepted: 30 December 2019

\begin{abstract}
Abstrak
Tujuan penelitian ini adalah untuk menguji pengaruh metode latihan dan koordinasi mata tangan terhadap akurasi pukulan forehand sidespin service tenis meja. Metode latihan dalam penelitian ini adalah distributed practice dan massed practice, sedangkan koordinasi mata tangan terdiri atas koordinasi tinggi dan rendah. Metode penelitian menggunakan metode eksprerimen desain fakorial 2x2. Subjek penelitian delapan mahasiswa UKM tenis meja UPI yang terbagi atas empat kelompok. Berdasarkan placed kelompok koordinasi tinggi dan rendah dengan perlakuan MDP, kelompok persepsi motorik tinggi dan rendah dengan perlakukan MMP. Penelitian ini dilaksanakan selama 16 kali pertemuan. Hasil penelitian menunjukan (1) metode latihan distributed practice lebih efektif meningkatkan sidespin service tenis meja; (2) Terdapat interaksi antara metode latihan dan tingkat koordinasi dalam meningkatkan sidespin tenis meja; (3) Metode latihan distributed practice lebih efektif digunakan pada kelompok koordinasi tinggi dalam meningkatkan sidespin service tenis meja; (4) Tidak terdapat pengaruh (pengaruhnya sama) metode latihan distributed practice dengan metode massed practice terhadap forehand sidespin service tenis meja pada kelompok koordinasi rendah. Kesimpulan dalam penelitian ini bahwa metode latihan distributed practice lebih efektif digunakan pada atlet yang memiliki tingkat koordinasi tinggi, sedangkan untuk atlet yang memiliki koordinasi rendah bisa menggunakan kedua metode latihan tersebut.
\end{abstract}

Kata Kunci: distributed practice; massed practice; akurasi forehand sidespin service tenis meja.

\section{Method of exercise and hand-eye coordination improves the accuracy of the forehand sidespin table tennis service}

\begin{abstract}
The purpose of this study was to examine the effect of the practice method and hand-eye coordination on the accuracy of forehand sidespin table tennis services. The training methods in this study are distributed practice and massed practice, while hand-eye coordination consists of high and low coordination. The research method uses the $2 \times 2$ factorial design experiment method. The research subjects were 8 UPI table tennis UKM students who were divided into four groups. Based on the high and low coordinated groups with MDP treatment, the high and low motor perception groups with MMP treatment. The study was conducted during 16 meetings. The results showed (1) The method of distributed practice was more effective in increasing the sidespin of table tennis service; (2) There was an interaction between the training methods and the level of coordination in improving the sidespin of table tennis; (3) The method of distributed practice was more effectively used in high coordination groups in improving the sidespin of table tennis service; (4) There is no influence (the same effect) on the method of distributed practice training with the massed practice method on the forehand sidespin table tennis service in the low coordination group. The conclusion in this study that the method of distributed practice is more effectively used in athletes who have a high level of coordination, whereas for athletes who have low coordination can use both methods of training.
\end{abstract}

Keywords: distributed practice; massed practice; accuracy of forehand sidespin table tennis service.

How to Cite: Safari, I., \& Saptani, E. (2019). Metode latihan dan koordinasi mata tangan meningkatkan akurasi forehand sidespin service tenis meja. Jurnal Keolahragaan, 7(2), 174-181.

doi:https://doi.org/10.21831/jk.v7i2.26788

d.

https://doi.org/10.21831/jk.v7i2.26788

\section{PENDAHULUAN}

Keterampilan psikologi, fisiologis teknis dan taktis dibutuhkan untuk menunjang perfor- mance dalam olahraga raket (Lees, 2003). Untuk melakukan keterampilan motorik yang terampil dalam olahraga pada tingkatan tertentu dibutuhkan kemampuan peseptual yang tinggi (Mori et 
al., 2002). Dalam olahraga yang menggunakan raket, kecepatan dan akurasi bola (misalkan: kapasitas untuk memukul ke area yang diinginkan) merupakan dua parameter teknis yang relevan untuk menggambarkan hasil pukulan (Girard \& Millet, 2009; Rota et al., 2014). Kecepatan stroke dalam tenis meja sangat tinggi sehingga membutuhkan responyang cepat dari pemain (Hung et al., 2007). Akpinar et al. (2012) pemain tenis meja memiliki kinerja yang lebih baik dari pada pemain tenis dan bulu tangkis dalam hal kecepatan stimulus tinggi.

Kecepatan bola yang tinggi dalam tenis meja dibutuhkan kemampuan salah satu komponen kebugaran jasmani yang dapat membantu dalam penguasaan keterampilan gerak, keterampilan gerak tersebut salah satunya yaitu koordinasi, koordinasi mata-tangan adalah kemampuan seseorang melakukan gerakan dengan efisien hasil dari menggabungkan pengilihatan dan gerakan tangan, kemampuan untuk melempar, memukul, menangkap dan menuntut hubungan kerja yang erat antara mata dan System Neomoscular (Yunus, 1992). Hoeger dan Hoeger (2013) integrasi sistem saraf dan otot untuk menghasilkan gerakan tubuh yang benar, graceful, dan harmonis disebut dengan koordinasi. Meskipun bukan hanya salah satu aspek tetapi kemampuan koordinasi dan keterampilan gerak merupakan faktor yang sangat signifikan dalam menguasai permainan tenis meja (Limoochi, 2006; Toriola et al., 2004; van Rossum \& Gagné, 1994).

Performance altet dapat ditunjang dengan bentuk latihan yang menunjang akan memberikan kontribusi kepada atlet dalam peningkatan performance. Proses dasar untuk mempersiakaan kinerja yang lebih tinggi dengan proses yang dirancang untuk mengembangkan kemampuan motorik dan psikologis untuk meningkatkan kemampuan seseorang merupakan hasil dari latihan (Singh, 2012).

Variasi metode latihan akan memotivasi atlet dalam berlatih, salah satunya metode latihan distributed practice dan massed practice. Distrubuted practice adalah masalah utama yang penting tidak hanya di lingkungan olahraga, tetapi juga dalam rehabilitation dan pendidikan. Keputusan paling penting yang harus diambil oleh guru, ahli terapi, atau pelatih adalah tentang bagaimana mendistribusikan keterampilan tertentu selama latihan. Dua poin yang sangat penting dalam proses ini yang pertama adalah menentukan durasi dan urutan sesi latihan dalam seminggu dan yang kedua adalah untuk menentukan interval antara kegiatan dan waktu istirahat
(Magill, 2011). Dalam mendistribusikan sesi latihan keseimbangan antara efek latihan dan efisiensi sangatlah penting. Efek latihan berarti belajar dengan skor kesalahan yang lebih sedikit, peningkatan pola gerak, akuisisi, dan transfer yang lebih baik ke keterampilan motorik. Ini biasanya dievaluasi dalam pembelajaran dan tes transfer. Sedangkan efisiensi berarti praktik yang mengarah pada penghematan ekonomi dan waktu, lebih sedikit cedera dan biaya praktik lainnya (Ahmadvand et al., 2016).

Metode latihan massed practice menjalankan periode latihan bersama seperti dalam hal berolahraga dengan istirahat pendek atau tanpa istirahat. Dengan kata lain praktik ini relatif berkelanjutan (Schmidt et al., 2018). Metode massed practice menurut (Lumintuarso, 2013) adalah metode berlatih gerakan terus menerus tanpa istirahat sampai waktu habis. Olahraga terus menerus meningkatkan kemampuan untuk mengontrol gerakan selama latihan dan akan merangsang kemampuan otot yang dibutuhkan dalam olahraga tertentu untuk membantu mencapai kinerja yang lebih baik. Sedangkan menurut (Wiwin et al., 2017) metode latihan massed practice adalah prinsip mengatur keterampilan latihan gilirannya bahwa pelaksanaan dilakukan terus menerus tanpa istirahat.

Setiap permainan net pada saat memulai pertandingan dimulai dengan serve, setiap reli dimulai dengan serve, karenanya, serve mewakili titik awal dari interaksi dinamis antara kedua lawan dan dapat mengganggu sistem dan menciptakan keuntungan bagi server selama konfrontasi (Gómez et al., 2017). Dalam siaran pers barubaru ini, Bialik (2016) menunjukkan keunggulan rata-rata untuk tim/pemain saat bermain di olahraga net Olimpiade. Serve memiliki keuntungan terbesar untuk server dalam tenis (lebih dari $60 \%$ ), Voli pantai (kurang dari 40\%). Dalam tenis meja, kepemilikan serve memberikan keuntungan bagi server (53\%).

Penelitian tentang metode latihan sudah banyak dilakakukan seperti yang dilakukakan oleh Zheng dan Jin (2016) dengan hasil penelitian bahwa metode latihan multi bola menghasilkan intensitas lebih dari $45 \%$ lebih tinggi dari pada pelatihan bola tunggal, waktu yang dibutuhkan untuk memukul 50\% lebih tinggi. Beban latihan multi bola secara signifikan lebih besar dari pada pelatihan bola tunggal. Metode pelatihan multibola memiliki efek yang jelas pada peningkatan tingkat teknis dan taktis pemain, kualitas dan keinginan khusus. Selanjutnya hasil penelitian Saleh (2015, p. 179) dengan judul Effects of 
training with multi-balls on some visual abilities and counter-attack skills for junior tabel tennis players dengan peserta sebanyak 15 atlet yang dipilih dari pemain tenis meja yunior kurang dari 15 tahun dari Zona Gharbia yang terdaftar di Federasi Tenis Meja Mesir dan pemain berpartisipasi dalam Kejuaraan Champions Zona di Mesir hasil penelitiannya adalah program pelatihan yang direkomendasikan memiliki efek signifikan pada pelatihan pemain tenis meja junior kurang dari 15 tahun, Pelatihan meotode multi-bola memiliki efek positif pada beberapa kemampuan visual pemain tenis meja junior kurang dari 15 tahun. Pelatihan metode multi-bola memiliki efek positif pada beberapa keterampilan counter attack dari pemain tenis meja junior kurang dari 15 tahun. Tes counter attack memiliki efek positif pada peningkatan persentase peningkatan setelah menerapkan program yang direkomendasikan. Penelitian yang dilakukan Tsetseli et al. (2010), menunjukkan bahwa yang paling penting kemampuan koordinasi untuk pemain tenis adalah diferensiasi kinestetik dan waktu reaksi. temuan penelitian ini dapat langsung diterapkan pada pelatihan tenis untuk meningkatkan teknik service. Kemampuan koordinasi sangat penting selama bermain tenis, dan perkembangan mereka sejak usia dini sangat penting. Pelatih yang bekerja dengan pemain muda dapat memasukkan latihan koordinasi khusus tenis ke dalam program pelatihan mereka.

Berdasarkan pendapat tersebut bahwa serve memberikan keuntungan bagi server untuk mendapatkan poin dalam olaharaga net. Tenis meja merupakan salah satu olahraga net, sehingga penguasaan serve sangatlah penting dikuasi oleh atlet untuk mendapatkan keuntungan poin dari melakukan serve. Berdasarkan observasi yang dilakukan pada anggota UKM Tenis Meja UPI masih terdapat kesalahan-kesalahan dalam melakukan serve dan kurangnya variasi dalam melakukan serve. Sehingga tujuan dari penelitian ini adalah untuk mengetahui pengaruh metode latihan distributed practice dan massed practice dalam meningkatkan sidespin service tenis meja.

\section{METODE}

Metode penelitian pada penelitian ini menggunakan metode eksperimen dengan desain penelitian factorial $2 \times 2$. Desain faktorial memperluas jumlah hubungan yang dapat diperiksa dalam penelitian eksperimental. Mereka pada dasarnya adalah modifikasi dari kelompok kontrol posttest-only atau desain kelompok kontrol pretest-posttest. Variasi dari desain ini mengguna- kan dua atau lebih kelompok perlakuan berbeda dan tidak ada kelompok kontrol (Fraenkel et al., 2012). Selain menggunakan desain factorial, dalam penelitian ini juga menggunakan desain single subjek. (Fraenkel et al., 2012) Penelitian subjek tunggal melibatkan pengumpulan data yang luas pada satu subjek pada suatu waktu. Berikut rancangan desain factorial $2 \times 2$ (Tabel 1).

Tabel 1. Desain Faktorial 2x2

\begin{tabular}{|c|c|c|}
\hline $\begin{array}{l}\text { Metode } \\
\text { Latihan }\end{array}$ & $\begin{array}{l}\text { Metode Latihan } \\
\text { (distributed } \\
\text { practice) } \\
\text { (A1) }\end{array}$ & $\begin{array}{c}\text { Metode } \\
\text { Latihan } \\
\text { (massed } \\
\text { practice) } \\
\text { (A2) }\end{array}$ \\
\hline $\begin{array}{l}\text { Kemampuan Tinggi } \\
\text { (B1) }\end{array}$ & A1B1 & A2B1 \\
\hline $\begin{array}{l}\text { Kemampuan Rendah } \\
\text { (B2) }\end{array}$ & A1B2 & $\mathrm{A} 2 \mathrm{~B} 2$ \\
\hline
\end{tabular}

Desain faktorial $2 \times 2$ ini akan menjadikan sampel menjadi empat kelompok yang terdiri dari kelompok yang memiliki tingkat koordinasi tinggi diberikan perlakuan metode latihan distributed practice (A1B1), kelompok yang memiliki tingkat koordinasi rendah diberikan perlakuan metode latihan distributed practice (A1B2), kelompok yang memiliki tingkat koordinasi tinggi diberikan perlakuan metode latihan massed practice (A2B1) dan kelompok yang memiliki tingkat koordinasi rendah diberikan perlakuan metode latihan massed practice (A2B2).

Subjek yang digunakan adalah mahasiswa UPI yang mengikuti Unit Kegiatan Tenis meja dengan tingkat keterampilan bukan pemula, semuanya memiliki pengalaman bermain dengan tingkat yang bervariasi dengan rentang usia dari 18 tahun hingga 25 tahun. Penentuan sampel didasarkan pada data yang diambil setiap pertemuan dimana subjek melakukan satu kali tes setiap kali pertemuan, data yang digunakan adalah menggunakan 16 kali pertemuan dikalikan satu kali tes yaitu 16 untuk satu subjek, dalam penelitian ini menggunakan delapan subjek sehingga untuk keseluruhan data adalah delapan dikalikan 16 yaitu 128, kemudian data tersebutlah yang dijadikan sebagai sampel dalam penelitian ini.

Sebelum melakukan perlakuan kepada subjek, peneliti melakukan tes koordinasi mata dan tangan terlebih dahulu kepada subjek. Selanjutnya pada tahap treatment menggunakan meja tenis meja sebanyak 8 meja, setiap meja di isi oleh dua subjek, kelompok MDPKT diberikan perlakuan menggunakan metode latihan distributed practice pada subjek koordinasi tinggi, kelompok MDPKR diberikan perlakuan metode latihan distributed practice pada subjek koordi- 
nasi tinggi, kelompok MMPKT diberikan perlakuan metode latihan massed practice pada subjek koordinasi tinggi dan kelompok MMPKR diberikan perlakuan metode latihan massed practice pada subjek koordinasi rendah.

Pelaksanaan kegiatan latihan berlangsung selama 16 kali pertemuan, dua kali seminggu, dengan asumsi jumlah latihan sebanyak 16 kali tersebut sudah dapat meningkatkan keterampilan teknik pukulan. Jumlah 16 kali latihan tidak termasuk dua kali tes yaitu satu kali tes koordinasi untuk mengelompokkan subjek, dan tes akhir berbentuk tes forehand sidespin service.

Analisis data dalam penelitian ini menggunakan analisis uji normalitas untuk menguji data normal atau tidak nya dengan asumsi Sig $>\alpha 0,05$ data berdistribusi normal, selanjutnya uji homogenitas untuk mengetahui data yang diujikan berdistribusi homogeny atau tidak dengan asumsi Sig $>\alpha 0,05$ maka data berdistribusi homogen, se- telah melakukan uji prasyarat selanjutnya dilakukan uji hipotesis dengan menggunakan uji two way annova untuk mengetahui perbedaan dari setiap kelompok dan terakhir dilakukan uji lanjut tukey dengan tujuan untuk membandingkan semua kelompok dengan asumsi Sig $<\alpha 0,05$ maka hipotesis diterima. Analisis data ini menggunakan pendekatan statistika dengan menggunakan aplikasi SPSS v.20.

\section{HASIL DAN PEMBAHASAN}

\section{Deskripsi Statistik}

Deskripsi hasil analisis data yang dilakukan dengan pendekatan statistika menunjukan data metode latihan distributed practice dan massed practice pada kelompok berkoordinasi rendah dan tinggi terhadap peningkatan forehand sidespin service tenis meja dijelaskan pada Tabel 2.

Tabel 2. Deskripsi Statistik Metode Latihan pada Kelompok Berkoordinasi Rendah dan Tinggi

\begin{tabular}{lcc}
\hline \multicolumn{1}{c}{ Kelompok } & Mean Test Pertemuan 1-14 & Standar Deviasi \\
\hline MDPKT & 4.03 & 0.645 \\
MDPKR & 3.54 & 0.434 \\
MMPKT & 3.20 & 0.333 \\
MMPKR & 3.74 & 0.555 \\
\hline
\end{tabular}

Tabel 3. Uji Two Way Annova

\begin{tabular}{lccccc}
\hline \multicolumn{1}{c}{ Source } & Type III Sum of Square & Mean Square & F & Sig. & Ket \\
\hline Corrected Model & $5.092^{\mathrm{a}}$ & 1.697 & 6.621 & 0.001 & Signifikan \\
MetodeLatihan*Koordinasi & 3.703 & 3.703 & 14.445 & 0.000 & Signifikan \\
\hline
\end{tabular}

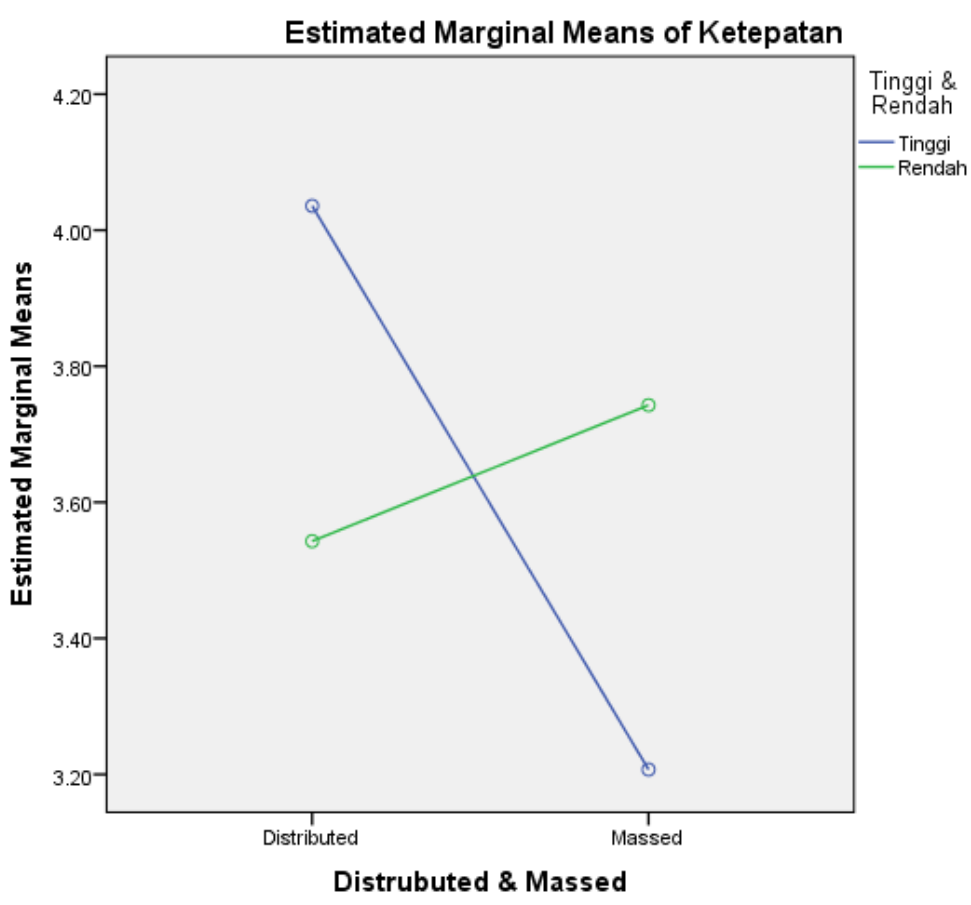

Gambar 1. Diagram Plot Metode Latihan dengan Tingkat Koordinasi 
Jurnal Keolahragaan 7 (2), 2019 - 178

Indra Safari, Entan Saptani

\section{Uji Hipotesis}

Setelah dilakukan uji prasyarat, selanjutnya dilakukan uji hipotesis dengan menggunakan statistic parametrik karena data berasal dari distribusi normal dan homogen. Uji parametrik dalam penelitian ini adalah uji two-way annova yang akan disajikan pada Tabel 5 .

\section{Hipotesis 1}

Berdasarkan Tabel 5 menunjukan bahwa nilai sig $0.001<0.05$, maka terdapat perbedaan pengaruh penggunaan metode latihan distributed practice dan metode massed practice dalam meningkatkan forehand sidespin service tenis meja. Dapat disimpulkan bahwa metode latihan distributed practice lebih baik dengan nilai ratarata 7,57 dibandingkan dengan massed practice dengan nilai rata-rata 6,94. Dengan demikian hipotesis 1 sesuai dengan hasil penelitian. Untuk memperkuat hasil temuan tersebut, peneliti mengkaji teori metode latihan. Menurut Roestiyah (2001) metode latihan adalah suatu cara mengajar dimana siswa melaksanakan kegiatan-kegiatan latihan agar siswa memiliki ketangkasan atau keterampilan yang lebih tinggi dari apa yang telah dipelajari. Penggunaan metode latihan bertujuan untuk memiliki keterampilan motoris/gerak, mengembangkan kecakapan intelek, memeiliki kemampuan menghubungkan sesuatu keadaan dengan hal lain.

Mahendra (2007) menjelaskan bahwa distributed practice menunjukkan sedikitnya waktu istirahat di antara ulangan atau tidak istirahat sama sekali. Praktek distribusi memerlukan istirahat di antara ulangannya minimal selama waktu pelaksanaannya. Christina dan Corcos (2004) melakukan peneliti untuk membandingkan peran massed practice dan distributed practice dalam pembelajaran jangka panjang dan menginstruksikan tugas-tugas motorik diskrit. Dalam penelitian ini, golf hit digunakan sebagai tugas diskrit yang hasilnya menunjukkan bahwa mereka yang berlatih sesuai dengan metode distributed practice menunjukkan kinerja yang lebih baik daripada kelompok yang berlatih sesuai dengan metode massed practice.

Pendapat tersebut mendukung hasil penelitian ini yang menunjukan metode latihan distributed practice lebih efektif dibandingkan dengan metode latihan massed practice dalam meningkatkan ketepatan forehand sidespin service tenis meja.

\section{Hipotesis 2}

Selanjutnya hasil pengolahan data pada Tabel 5 (metodeLatihan*Koordinasi) menunjukkan nilasi Sig $0.000<0.05$, maka terdapat interaksi antara metode latihan dengan tingkat koordinasi terhadap peningkatan forehand sidespin service tenis meja. Sehingga terjadi efek kombinasi yang unik antara media latihan dengan tingkat koordinasi atlet, dengan demikian hipotesis 2 diterima. Kemampuan koordinasi sangat penting untuk mengembangkan dan melakukan teknik gerakan yang optimal (Christina \& Corcos, 2004; Druckman \& Swets, 1988). Untuk pemain bola basket (Zwierko et al., 2005) menunjukkan bahwa kemampuan koordinasi seperti orientasi, diferensiasi, reaksi, keseimbangan, dan keterampilan teknis adalah bagian penting dari latihan para pemain bola basket. (Derri et al., 2000) mengemukakan bahwa kemampuan kiestetik berkembang pesat sampai usia sepuluh dan atlet yang terlatih cukup hebat pada kemampuan ini. Kinestisis sangat penting ntuk perkembangan dan keterampilan motoric baru.

Berdasarkan teori tersebut yang mendukung kepada penelitian yang dilakukan dengan hasil adanya efek kombinasi (interaksi) antara metode latihan dan tingkat koordinasi dalam meningkatkan ketepatan forehand sidespin service tenis meja. Hal ini dibuktikan dengan hasil grafik data hasil pendekatan seara statistika seperti pada Gambar 1.

\section{Hipotesis 3}

Pada analisis data Tabel 5 menunjukan adanya interaksi anatar metode latihan dengan tingkat koordinasi, maka dilakukan uji lanjut Tukey untuk mengetahui perbedaan pada kelompok-kelompok tersebut. Hasil uji Tukey dijelaskan pada Tabel 6.

Tabel 6. Uji Tukey Kelompok Koordinasi Tinggi

\begin{tabular}{|c|c|c|c|}
\hline Koordinasi & Mean & Mean Difference $(I-J)$ & Sig \\
\hline Distribusi & 4.03 & $.829 *$ & \\
\hline 11ngg1 Massed & 3.20 & $-.829 *$ & \\
\hline
\end{tabular}

Berdasarkan Tabel 6 menunjukan nilai Sig $0.000<0.05$, maka terdapat perbedaan pengaruh metode latihan distributed practice dengan metode massed practice terhadap forehand sidespin service tenis meja pada kelompok koordinasi tinggi. Dengan demikian metode latihan distributed practice lebih efektif digunakan pada kelompok koordinasi tinggi dengan nilai rata-rata kelompok 4.03 dibandingkan dengan metode 
massed practice yang memiliki nilai rata-rata 3.20 untuk meningkatkan forehand sidespin service tenis meja, maka hipotesis 3 diterima.

Gerakan dan koordinasi kelompok otot besar melibatkan keterampilan Gross skills. Gross skill sering membutuhkan tangan untuk berkoordinasi dengan mata. Gross skill biasanya digunakan dalam bermain dan olahraga (Gordon \& Inder, 2000). Keterampilan ini memungkinkan untuk mengendalikan tubuh mereka, memanipulasi lingkungan mereka dan menunjukkan keterampilan yang kompleks dan pola perkembangan yang terlibat dalam olahraga dan kegiatan rekreasi lainnya (Haywood \& Getchell, 2019; National Association for Sport, 2004). Keterampilan motorik kasar dianggap sebagai pendahulu untuk keterampilan gerakan yang lebih maju dan keterampilan olahraga spesifik (Coker, 2017; Haywood \& Getchell, 2019; Payne \& Isaacs, 2017; Ulrich \& Sanford, 2000) dan dimasukkan dalam standar konten nasional dalam pendidikan jasmani di beberapa negara.

Schmidt dan Wrisberg (2008) pembelajaran motorik adalah serangkaian proses yang terkait dengan praktik atau pengalaman yang mengarah pada peningkatan kemampuan permanen untuk kinerja yang terampil. Agar perubahan tingkat kinerja terampil dianggap sebagai karena pembelajaran, perubahan tersebut harus relatif permanen. Banyak faktor yang memengaruhi tingkat kinerja terampil sesaat, beberapa di antaranya bersifat sementara. Misalnya, keterampilan dapat dipengaruhi oleh obat-obatan, kurang tidur, suasana hati, stres, motivasi, dan banyak faktor lainnya.

Berdasarakan teori tersebut bahwa gerakan dan koordinasi (Gross Skill) sebagai pendahulu keterampilan gerak, ditambah dengan pembelajaran motorik dengan menggunakan metode latihan tentu akan mempercepat penguasaan pembelajaran gerak sehingga terjadi gerakan yang permanen. Teori tersebut mendukung hasil penelitian ini yang menunjukan bahwa metode latihan distributed practice lebih efektif digunakan untuk kelompok atlet yang memiliki koordinasi tinggi dalam meningkatkan ketepatan forehand sidespin service tenis meja.

Hipotesis 4

Hasil analisis uji lanjut kelompok koordinasi rendah akan dijelaskan pada Tabel 7 . Berdasarkan Tabel 7 menunjukan nilai Sig 0.301 $>0.05$, maka tidak terdapat pengaruh metode latihan distributed practice dengan metode massed practice terhadap forehand sidespin service tenis meja pada kelompok koordinasi rendah. Dengan demikian tidak ada beda atau sama pengaruh antara metode latihan distributed practice dengan metode massed practice terhadap forehand sidespin service tenis meja pada kelompok koordinasi rendah. Selanjutnya dilihat dari nilai rata-rata kelompok metode latihan massed practice memiliki nilai rata-rata 3.74 lebih besar disbandingkan dengan kelompok metode latihan distributed practice yang meiliki nilai rata-rata 3.54 . Sehingga dapat ditarik kesimpulan bahwa penggunaan metode latihan massed practice lebih efektif dibandingkan dengan metode latihan distributed practice pada kelompok koordinasi rendah dalam meningkatkan forehand sidespin service tenis meja. Maka hipotesis empat tidak sesuai dengan hasil penelitian.

Tabel 7. Uji Tukey Kelompok Koordinasi Rendah

\begin{tabular}{cccc}
\hline Koordinasi & Mean & Mean Difference $(I-J)$ & Sig. \\
\hline \multirow{2}{*}{ Rendah Distribusi } & 3.54 & -.200 & .301 \\
Massed & 3.74 & .200 & .301 \\
\hline
\end{tabular}

Perbedaan penggunaan rubber/karet bet di setiap atlet memberikan dampak terhadap akurasi, karena karakteristik rubber yang berbedabeda antara satu dengan yang lainnya dan memiliki spesifikasi masing-masing. hasil penelitian dari Rusdiana dan Ichsan (2017) nilai kecepatan rata-rata jenis karet bintik kedalam lebih tinggi dari jenis karet keras. Karet bintik keluar adalah karet dengan bintik yang menghadap ke luar karakteristik karet ini sangat baik untuk melakukan smash tetapi tidak cocok untuk melakukan spin. Kecepatan dihasilkan tidak hanya oleh kinerja lembaran atas, tetapi juga oleh tekanan bola pada spons sehingga permukaan melebar ketika bola berdampak. Kimura et al. (2012) Kinerja raket tenis meja terutama tergantung pada kualitas karet raket tenis meja.

Pendapat tersebut mendukung hasil penelitian yang menunjukan tidak terdapat perbedaan atau dikatakan sama berpengaruh antara metode latihan distributed practice dan massed practice pada kelompok koordinasi rendah dalam meningkatkan ketepatan forehand sidespin service tenis meja.

\section{SIMPULAN}

Simpulan penelitian ini adalah penggunaan metode latihan distributed practice lebih baik dibandingkan dengan massed practice. Untuk atlet yang memiliki koordinasi tinggi lebih baik menggunakan metode latihan distributed practice untuk meningkatkan ketepatan forehand 
sidespin service tenis meja. Untuk atlet yang memiliki koordinasi rendah kedua metode latihan berpengaruh sama untuk meningkatkan ketepatan forehand sidespin service tenis meja. Peneliti merekomendasikan kepada peneliti selanjutnya yang ingin melakukan penelitian tentang metode latihan distributed practice dan massed practice untuk mengukur kecepatan spin (putaran) bola dalam forehand sidespin service tenis meja.

\section{DAFTAR PUSTAKA}

Ahmadvand, R., Kiani, S. M. A., \& Shojae, M. (2016). The effect of mass \& distributed practice on and complex skills in volleyball. Turkish Journal of Kinesiology, 2(3),

49-55. https://dergipark.org.tr/en/pub/turkjkin/iss ue/26721/282766? publisher=turkjkin;

Akpinar, S., Devrilmez, E., \& Kirazci, S. (2012). Coincidence-anticipation timing requirements are different in racket sports. Perceptual and Motor Skills, 115(2), 581593.

https://doi.org/10.2466/30.25.27.PMS.115 $.5 .581-593$

Bialik, C. (2016). Serving is a disadvantage in some Olympic sports. FiveThirtyEight.

Christina, R. W., \& Corcos, D. M. (2004). Coaches guide to teaching sport skills (M. T. Aghdasi (trans.)). Tabriz University Pub.

Coker, C. A. (2017). Motor learning and control for practitioners. McGraw Hill.

Derri, Mertzanidou, \& Tzetzis. (2000). Assessment of dynamic balance and body coordination in female athletes of rhythmic and gymnastics, 9-15 years old. Exercise and Society, 26, 55-62.

Druckman, D., \& Swets, J. A. (1988). Enhancing human performance: Issues, theories, and techniques. National Academy Press.

Fraenkel, J. R., Wallen, N. E., \& Hyun, H. H. (2012). How to design and evaluate research in education. McGraw-Hill Humanities/Social Sciences/Languages.

Girard, O., \& Millet, G. P. (2009). Neuromuscular fatigue in racquet sports. Physical Medicine and Rehabilitation Clinics of North America, 20(1), 161-173. https://doi.org/10.1016/j.pmr.2008.10.008

Gómez, M.-Á., García-de-Alcaráz, A., \& Furley, P. (2017). Analysis of contextual-related variables on serve and receiving performances in elite men's and women's table tennis players. International Journal of Performance Analysis in Sport, 17(6), 919-933.

https://doi.org/10.1080/24748668.2017.14 07208

Gordon, B., \& Inder, T. (2000). The competency levels of third year pre-service primary teachers in performing and learning fundamental motor skills. Journal of Physical Education New Zealand, 33(3), 53-66.

Haywood, K. M., \& Getchell, N. (2019). Life span motor development. Human Kinetics.

Hoeger, W. W. K., \& Hoeger, S. A. (2013). Principles and labs for physical fitness. Cengage Learning.

Hung, T., Wu, C., Lin, J., Wang, J. S., \& Tsai, H. F. (2007). The relationship between stimulus preceding EEG alpha power and reaction time in elite table tennis players. Sports Science Research, 26(3), 11-17.

Kimura, Y., Okamura, M., Harioka, T., Hara, T., Nakasato, A., Ishiyama, T., \& Matsukawa, T. (2012). [Suspected diltiazem intoxication resulting in repeated asystole after the induction of anesthesia]. Masui. The Japanese Journal of Anesthesiology, 61(1), 104-107. http://europepmc.org/abstract/MED/2233 8872

Lees, A. (2003). Science and the major racket sports: A review. Journal of Sports Sciences, 21(9), 707-732. https://doi.org/10.1080/026404103100014 0275

Limoochi. (2006). A Survey of Tabel Tennis Coaches'Opinions of Some Criteria in Talent Identification. International Journal of Tabel Tennis Science, 6, 280287.

Lumintuarso, R. (2013). Teori kepelatihan olahraga. Lankor.

Magill, R. A. (2011). Motor learning and control: Concepts and applications. McGraw-Hill.

Mahendra, A. (2007). Teori belajar mengajar motorik. FPOK UPI.

Mori, S., Ohtani, Y., \& Imanaka, K. (2002). Reaction times and anticipatory skills of karate athletes. Human Movement Science, 21(2), 213-230. https://doi.org/10.1016/S01679457(02)00103-3

National Association for Sport. (2004). Moving into the future: National physical education standards: A guide to content 
and assessment. McGraw-Hill Humanities Social.

Payne, V. G., \& Isaacs, L. D. (2017). Human motor development: A lifespan approach. Routledge.

Roestiyah, N. K., \& Suharto, Y. (1985). Strategi belajar mengajar. PT. Bina Aksara.

Rota, S., Morel, B., Saboul, D., Rogowski, I., \& Hautier, C. (2014). Influence of fatigue on upper limb muscle activity and performance in tennis. Journal of Electromyography and Kinesiology, 24(1), 90-97.

https://doi.org/10.1016/j.jelekin.2013.10.0 07

Rusdiana, A., \& Ichsan, D. N. (2017). Rubber bat effect of maximal ball velocity in table tennis. IOP Conference Series: Materials Science and Engineering, 180(1), 012231. https://doi.org/10.1088/1757899X/180/1/012231

Saleh, S. F. (2015). Effects of training with multiballs on some visual abilities and counterattack skills for junior table tennis players. Journal of Applied Sports Science, 5(2). http://jass.alexu.edu.eg/index.php/JASS/ar ticle/view/58

Schmidt, R. A., Lee, T. D., Winstein, C., Wulf, G., \& Zelaznik, H. N. (2018). Motor control and learning: A behavioral emphasis. Human Kinetics.

Schmidt, R. A., \& Wrisberg, C. A. (2008). Motor learning and performance: A situationbased learning approach. Human Kinetics.

Singh, H. (2012). Science of sports training. Chawla Offset Printers.

Toriola, A. L., Toriola, O. M., \& Igbokwe, N. U. (2004). Validity of specific motor skills in predicting table-tennis performance in novice players. Perceptual and Motor
Skills,

98(2),

584-586.

https://doi.org/10.2466/pms.98.2.584-586

Tsetseli, M., Malliou, V., Zetou, E., Michalopoulou, M., \& Kambas, A. (2010). The effect of a coordination training program on the development of tennis service technique. Journal Biology of Exercise, 6(1), 29-36. https://doi.org/10.4127/jbe.2010.0033

Ulrich, D. A., \& Sanford, C. B. (2000). Test of gross motor development: examiner's manual. Austin.

van Rossum, J. H. A., \& Gagné, F. (1994). Rankings of predictors of athletic performance by top level coaches. European Journal of High Ability, 5(1), 68-78. https://doi.org/10.1080/093744594005010 7

Wiwin, D., Mintarto, E., \& Nurkholis, N. (2017). The influence of methods massed practice and distributed practice model on the speed and accuracy of service tennis courts. Journal of Physical Education Health and Sport, 4(1), 18-22. https://doi.org/10.15294/jpehs.v4i1.7047

Yunus, M. (1992). Bolavoli olahraga pilihan. Depdikbud Direktorat Jenderal Pendidikan Tinggi.

Zheng, W., \& Jin, K. (2016). Multi ball training method: A new attempt of table tennis training in colleges and universities. Proceedings of 2016 5th International Conference on Social Science, Education and Humanities Research, SSEHR, 261$264 . \quad$ https://doi.org/10.2991/ssehr16.2016 .55

Zwierko, T., Lesiakowski, P., \& Florkiewicz, B. (2005). Selected aspects of motor coordination in young basketball players. Human Movement Science, 6, 124-128. 